Bangladesh J. Sci. Res. 29(2): 111-122, 2016 (December)

\title{
PHYSICO-CHEMICAL PROPERTIES AND NUTRIENT CONTENT OF SOME SLOW PYROLYSIS BIOCHARS PRODUCED FROM DIFFERENT FEEDSTOCKS
}

\author{
Mahmudul Islam Piash, Md. Faruque Hossain ${ }^{1}$ and Zakia Parveen* \\ Department of Soil, Water \& Environment, University of Dhaka, \\ Dhaka-1000, Bangladesh
}

\begin{abstract}
Six slow pyrolysis biochars viz. farmyard manure (FM), water hyacinth (WH), domestic organic waste (DW), quick compost (QC), corn cob (CC) and rice straw (RS) were analyzed for their physical and chemical properties. Biochar yielding capacity varied from 34 to $51 \%$, depending on the used feedstock. Water hyacinth biochar exhibited the highest water holding capacity (495\%), whereas corn cob biochar had the lowest (146\%) regardless of its highest pore volume. Brunauer-Emmett-Teller (BET) specific surface area was found maximum among the plant derived biochars except corn cob. Rice straw biochar exhibited the least mean pore diameter while highest in domestic organic waste. All biochars possessed $\mathrm{pH}$ values more than 9. CEC of water hyacinth (WH) was highest, while lowest was in quick compost (QC) biochar. Smallest average particle size $\left(0.54 \mu \mathrm{m}^{2}\right)$ was exhibited by water hyacinth biochar. Organic carbon content ranged from 33 to $49 \%$. Nutrient (N, P, K and S) status of biochar produced from domestic organic waste (DW) was found the maximum compared to the rest and corn cob (CC) biochar showed the lowest nutritional value.
\end{abstract}

Key words: Pyrolyzed biochars, feedstocks, organic carbon, nutrient status, SEM

\section{Introduction}

Biochar, a carbon rich product obtained by heating biomass in an oxygen limited environment for $\mathrm{C}$ sequestration or agricultural or environmental management practices. It has drawn enormous attention of scientists to be used as soil amendment due to its ability for long term improvements in soil health along with significant effects on soil population. Pyrolytic biochar is described as an effective soil conditioner, as biochar may improve soil physical properties such as soil water retention, specific surface area, porosity, aggregation, hydraulic conductivity and reduce bulk density (Ayodele et al. 2009). Biochar also improves the soil chemical properties like ion exchange capacity, soil reaction, organic matter content, nutrient retention and $\mathrm{N}$ use efficiency (Chan and Xu 2009).

The significant changes in soil properties through biochar application have shown to influence soil biological processes with considerable propositions for soil biogeochemistry (Lehmann et al. 2011). Besides, C storage and heavy metal immobilization ability has given it extra priority to environmental scientists. Thermochemical alteration during pyrolysis changes constituent $\mathrm{C}$ compounds to yield materials that are depleted of $\mathrm{H}$ and $\mathrm{O}$ and higher in aromatic $\mathrm{C}$ (Chan and $\mathrm{Xu}$ 2009). Carbon captured in the biomass by photosynthesis would have been eventually returned to

*Author for correspondence: <zakiaparveen1@yahoo.ca>. ${ }^{1}$ American International University-Bangladesh, Kamal Ataturk Avenue, H \# 58/B, R \# 21, Banani, Dhaka-1213, Bangladesh. 
the atmosphere but biochar can remain sequestered in soils for hundreds to even thousands of years (Preston and Schmidt 2006). People tasked with solving waste management issues might consider biochar's ability to reduce odor, volume and $\mathrm{CH}_{4}$ emission and upgrade to a long lasting and more precious form of carbon (Qayyum et al. 2014).

Biochar yield and its physiochemical properties vastly depend on pyrolysis condition and the feedstock used (Ronsse et al. 2013). In addition, soil properties and intended crop require different properties of biochar and all biochars have not demonstrated improved crop yields (Deenik et al. 2010). Hence, the variations among biochar properties have to be well evaluated as a function of feedstock type and the production condition with respect to definite temperature. So far, biochar characterization has mainly focused on wood, crop or animal residue derived biochars to utilize as fuel or to apply in soils. The probability of producing biochars from household or agricultural garbage and their characterization have not been paid much attention. Additionally, the shortage of feedstocks in developing countries has made it rather difficult to consider biochar as a soil amendment. Selection of quality biochar feedstocks and production process might make it a rational tool for maintaining soil health and environmental standards.

Therefore, the main objective of this study is to identify the physicochemical properties of biochar produced from easily available feedstocks and how these properties varied by feedstock type and pyrolysis.

\section{Materials and Methods}

Feedstock collection and preparation: Farmyard manure (FM), water hyacinth (WH) and rice straw (RS) were collected from Sreenagar Upazila of Munsigonj district, Bangladesh. The domestic organic waste (DW) was collected from a typical apartment building's daily waste at Uttara, Dhaka. The quick compost was manufactured by Proshika (an NGO) with the ratio of cowdung, rice bran and oil cake at $4: 2: 1$. Corn cob was collected from Nawabganj Upazila of Dinajpur district which is one of the highest corn producing regions of the country. After collection of the feedstocks, those were air dried for several days and grinded into small pieces $(\leq 1$ $\mathrm{cm}$ ) for facilitating uniform heating in the pyrolysis kiln.

Biochar production process and analysis: A specially designed air-tight steel kiln was prepared for biochar production having couple of one way holes in it, restricting air entry into the pyrolysis chamber. Probe of a thermometer (Model: TM-902C) capable of measuring temperature ranging from -50 to $750^{\circ} \mathrm{C}$ was inserted right at the middle of the kiln. Other holes at the top of the kiln were to facilitate the exit of produced syngas (usually $\mathrm{H}_{2}$ and $\mathrm{CO}$ ). The pyrolysis was done on a gas stove ensuring uniform heating and desired production temperature. The feedstocks were kept on the kiln for further half an hour (residual time) after syngas emission was virtually ceased. After completion of pyrolysis and sufficient cooling, biochars were weighed, grounded and passed through a $2 \mathrm{~mm}$ sieve for further preservation and analysis. 
The production temperature was controlled at $380 \pm 20^{\circ} \mathrm{C}$ as to maintain uniformity in manufacturing of all the biochars. The yielding capacity of biochars at definite temperature was calculated using the following equation:

Yielding capacity $(\%)=\frac{\text { Mass of biochar produced }}{\text { Dry mass of feedstock }} \times 100 \%$

To determine the water holding capacity by mass ASTM (2010) method was followed. BET specific surface areas were obtained from nitrogen adsorption-desorption isotherms measured by Belsorp mini II (BEL Japan Inc.) at $77 \mathrm{~K}$, using the Brunauer, Emmett, and Teller (BET) method (Cabrera et al. 2011). The morphological properties of biochars were analyzed by Scanning Electron Microscopic (SEM) imaging. A range of SEM images (Magnification: 500 $\times$ to $2000 \times$ ) were captured with a JEOL JSM-6490 operating at 20KV at the Center for Advanced Research in Sciences (CARS), University of Dhaka. Image analysis was done with ImageJ version 2.0 with appropriate threshold and size range values.

The $\mathrm{pH}$, electrical conductivity ( $1: 10$ ratio) and cation exchange capacity (CEC) of biochar samples were measured as described in Rayment and Higginson (1992). Organic carbon of the feedstock and biochar were determined by wet oxidation method of Walkley and Black (1934). Biochars conversion efficiency of carbon and other nutrients were determined with the equation described in Naeem et al. (2014). Total $\mathrm{N}$ of the samples was determined by Kjeldahl steam distillation method (Jackson 1962). The concentration of P, K and S in feedstocks and biochars were analyzed after digestion with nitric-perchloric acid (Jackson 1962). Total P was measured colorimetrically using a spectrophotometer by developing yellow color with vanadomolybdate, total $\mathrm{K}$ by flame photometer and total $\mathrm{S}$ by turbidimetric method using spectrophotometer (Jackson 1962).

Statistical analyses were done by using Microsoft Excel 2010 and Stata version 12.0.

\section{Results and Discussion}

Yielding capacity and consecutive weight loss: The yielding capacity of biochars greatly varied depending on the feedstock type because a feedstock material typically comprises labile and recalcitrant oxygen and hydrogen containing fractions (Rutherford et al. 2013), the earlier one is rapidly lost after the initial heating which causes the massive weight loss of feedstock. The corn cob is the only feedstock that converted more than $50 \%$ of its mass to biochar allowing it to yield highest. The farmyard manure biochar recovered lowest amount i.e. about $35 \%$ of its feedstock mass may be due to high water and volatile content. Quick compost biochar demonstrated the second highest yielding capacity and the other biochar's recovery was quite similar ranging from about 40 to $42 \%$. In terms of feedstocks per cent weight loss, farmyard manure biochar lost the highest weight during its manufacturing (Fig. 1). Usually, among the different biochar types, 
woody and animal manure derived biochars show a larger weight loss as they contain higher volatile materials than non woody biochars like rice straw (Enders et al. 2012).

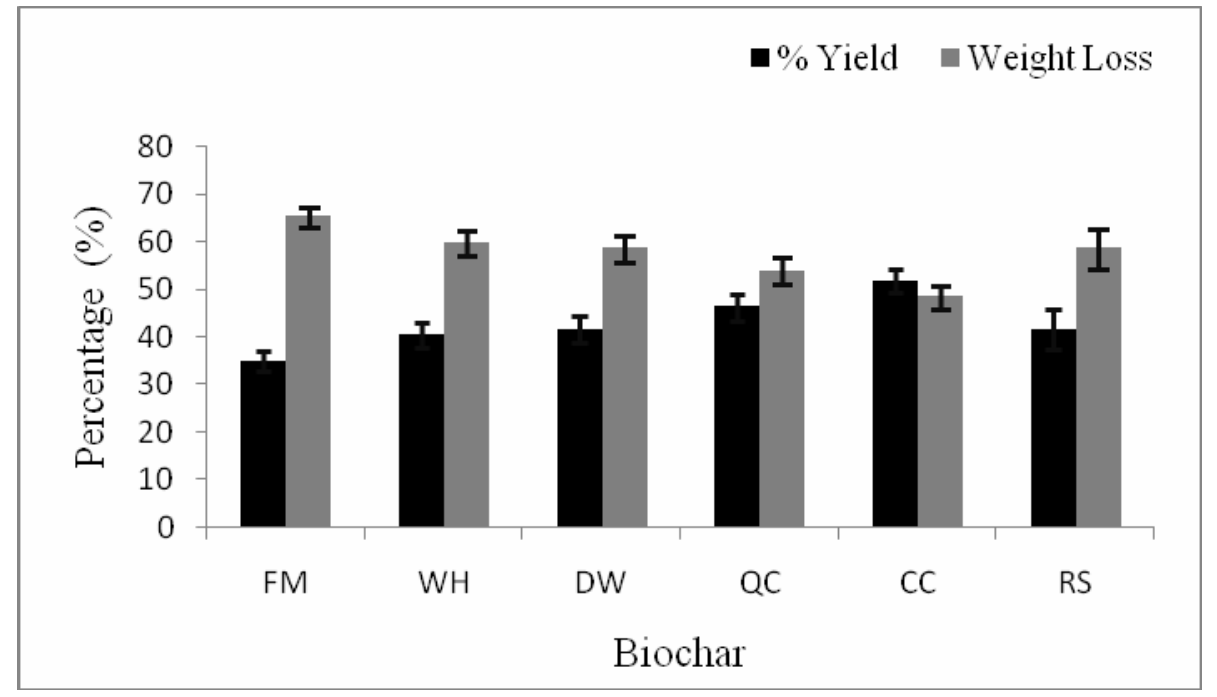

Fig. 1. Yielding capacity and consecutive weight loss (\%) of different biochars.

Physical characterization of biochars: It is widely accepted that modern agriculture depends enormously on chemical fertilizers and irrigation. Unsustainable land management practices have led in many areas to unproductive sandy soils with reduced water holding capacity. Results demonstrated high water holding capacity of biochars with considerable difference between plants derived biochars and the rest (Table 1). The water hyacinth biochar possessed the highest water retention of $495 \%$ that is nearly three times more than that of Quick compost which may be due to

Table 1. Water holding capacity (\%), mean pore diameter $(\mathrm{nm})$, average particle size $\left(\mu^{2}\right)^{2}$ and area occupied by particles (\%) in biochar.

\begin{tabular}{lllllll}
\hline \multirow{2}{*}{ Properties } & \multicolumn{5}{c}{ Different biochars } \\
\cline { 2 - 7 } & FM & WH & DW & QC & CC & RS \\
\hline $\begin{array}{l}\text { Water holding } \\
\text { capacity }\end{array}$ & $251 \pm 2.82$ & $495 \pm 11.39$ & $345 \pm 5.72$ & $146 \pm 2.76$ & $330 \pm 7.14$ & $479 \pm 12.32$ \\
$\begin{array}{l}\text { Mean pore } \\
\text { diameter }\end{array}$ & $25.26 \pm 0.11$ & $19.1 \pm 0.13$ & $28.6 \pm 0.23$ & $12.86 \pm 0.10$ & $18.8 \pm 0.10$ & $9.35 \pm 0.06$ \\
$\begin{array}{l}\text { Average particle } \\
\text { size }\end{array}$ & $2.91 \pm 0.06$ & $0.54 \pm 0.01$ & $0.91 \pm 0.02$ & $3.15 \pm 0.06$ & $17.8 \pm 0.16$ & $3.79 \pm 0.08$ \\
$\begin{array}{l}\text { Area covered by } \\
\text { particles }\end{array}$ & $13.16 \pm 0.26$ & $6.52 \pm 0.13$ & $13.4 \pm 0.27$ & $18.55 \pm 0.37$ & $1.85 \pm 0.04$ & $10.8 \pm 0.22$ \\
\hline
\end{tabular}

‘ \pm ' standard deviation. 
increased porosity of water hyacinth. Rice straw biochar demonstrated the second highest water retention of $479 \%$ followed by the domestic organic waste biochar $(345 \%)$. Biochar could be a competent amendment to light soils, specially for newly developed charlands with high sand deposit because of its high water holding capacity.

Mean pore diameter of biochars ranges from 9.35 to $28.56 \mathrm{~nm}$. Rice straw biochar had the lowest mean pore diameter while highest in domestic organic waste biochar. Water holding capacity and mean pore diameter illustrated a non-significant negative correlation. The pore distribution and specific surface area characterize the most vital physical properties of biochar for the enhancement of soil properties such as soil adsorption capacity and water retention ability. Literature shows that, biochar production at higher temperature and longer residence time (Ronsse et al. 2013) generally leads to an increase in total surface area, compared to the production at lower temperatures.

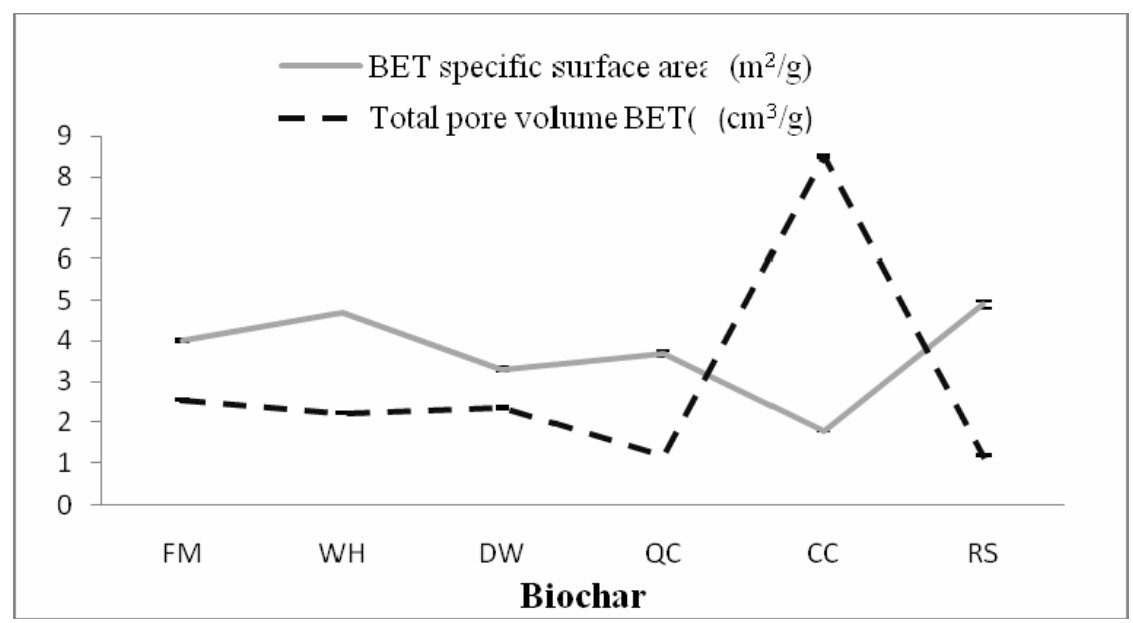

Fig. 2. Relationship between BET specific surface area and total pore volume.

BET specific surface area analysis revealed that corn cob biochar had the lowest surface area of $1.8 \mathrm{~m}^{2} \mathrm{~g}^{-1}$. Despite of being plant derived biochar, rice straw had the highest surface area of 4.9 $\mathrm{m}^{2} \mathrm{~g}^{-1}$ followed by water hyacinth $\left(4.7 \mathrm{~m}^{2} \mathrm{~g}^{-1}\right)$. Materials with greater surface area provides site to fix more nutrients and heavy metals. Farmyard manure, quick compost and domestic organic waste had specific surface area of 4.0, 3.7 and $3.3 \mathrm{~m}^{2} \mathrm{~g}^{-1}$, respectively (Fig. 2). The BET specific surface area and total pore volume were inversely correlated at 5\% level which means biochars with comparatively high pore volume had lower BET specific surface area and vice versa.

Optimizing biochar performance, feedstock selection and manufacturing conditions demand a comprehensive understanding of structure and particle distribution. Biochars are typically comprised of abundant minerals and organic structures. The surface morphology of all the biochar materials was highly diverse in structural composition. After analyzing the images with imageJ software, it is clear that (Table 1) corn cob Biochar's average particle size $\left(17.80 \mu \mathrm{m}^{2}\right)$ was the 
biggest along with its highest pore volume (Fig. 3). However, this particular Biochar's area occupied by particles in surprisingly low which is 1.85 per cent. In contrast, water hyacinth biochar possessed the smallest average particle size $\left(0.54 \mu \mathrm{m}^{2}\right)$ and second lowest area occupied by particles $(6.52 \%)$. The highly spongy and honeycomb like porosity of these biochars may grant high surface area which are likely to increase soil aeration, water holding capacity, and nutrient retention when incorporated in soil. Quick compost biochar shows the highest area of particles $(18.55 \%)$ that reveals it had lowest area of pores.
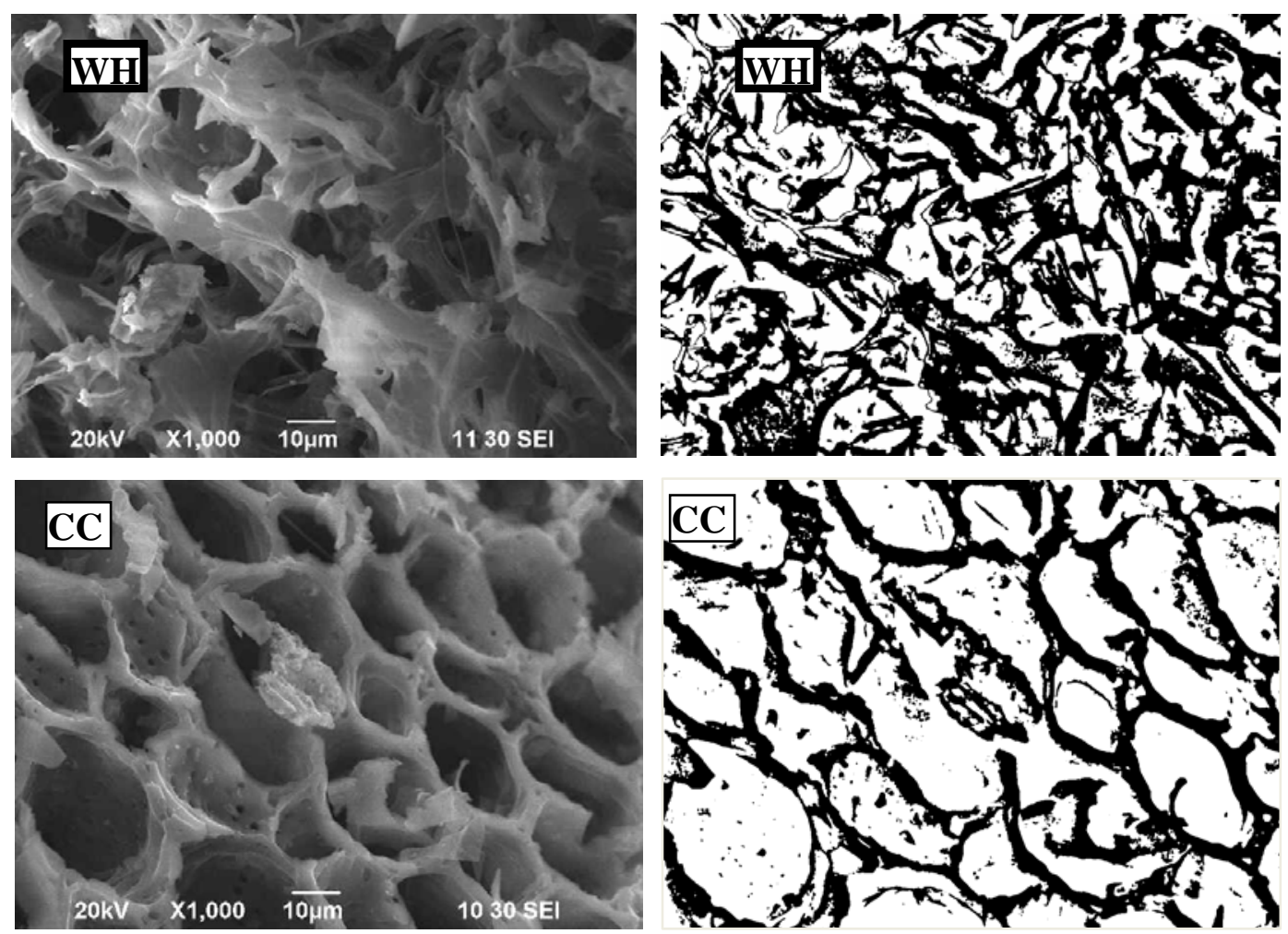

Fig. 3. SEM images $(1000 \times)$ of WH and CC biochar before and after analysis.

Chemical characterization of biochars: All biochars were found to be alkaline in nature $(\mathrm{pH}$ 9.0 to 10.5) due to high dissolution of base cations (Fig. 4). High production temperature increases the $\mathrm{pH}$ value of biochars probably as a consequence of the relative concentration of non-pyrolyzed inorganic elements that are already present in the original feedstocks (Novak et al. 2009). Biochar's alkalinity can be attributed to four broad categories: surface organic functional groups, carbonates, soluble organic compounds and other inorganic alkalis including oxides, hydroxides, sulfates, sulfides, and orthophosphates (Cheah et al. 2014). Increased $\mathrm{pH}$ of biochar amended acid soils may help to reduce $\mathrm{Al}$ toxicity and increase $\mathrm{P}$ availability. 


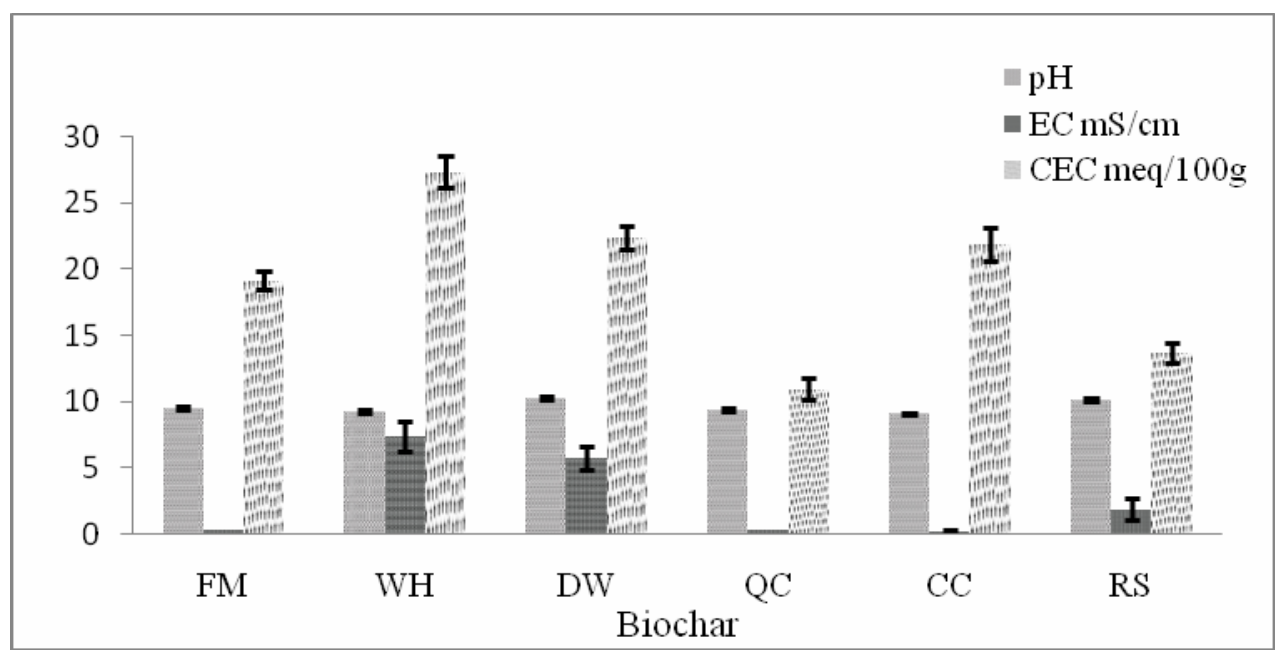

Fig. 4. pH, electrical conductivity (EC) and cation exchange capacity (CEC) of biochars.

Electrical conductivity (EC) was very high for biochars produced from WH, DW and RS and other three biochars had relatively lower EC (Fig. 4). High EC results might be due to high soluble salt concentrations. Biochars produced from water hyacinth and domestic organic waste demonstrated higher EC ( 7.38 and $5.69 \mathrm{mS} / \mathrm{cm}$, respectively), that might be due to their high $\mathrm{K}$ content (Table 3). Cation exchange capacity (CEC) indicates the ability of biochar to hold cationic nutrients. Soils with high CEC values are able to retain cationic fertilizers $\left(\mathrm{K}^{+}\right.$and $\left.\mathrm{NH}_{4}^{+}\right)$in the root zone and prevent nutrient leaching. The WH biochar showed highest CEC $(27.35 \mathrm{meq} / 100 \mathrm{~g})$ which is almost double than most mineral soils $(\leq 15 \mathrm{meq} / 100 \mathrm{~g})$ indicating that, this particular biochar could be an interesting soil amendment for sandy soils (Sposito 1989). Quick compost biochar had the lowest CEC that is $10.94 \mathrm{meq} / 100 \mathrm{~g}$ followed by rice straw biochar (13.67 meq/100g). Meszaros et al. (2007) predicted that $\mathrm{K}, \mathrm{Ca}, \mathrm{Mg}, \mathrm{Na}$ and $\mathrm{P}$ in the biomass promote the formation of O-containing groups on biochar surface during pyrolysis, resulting in higher CEC. Biochars with high CEC can also be an environmental management option for remediating soil or water contaminated with heavy metals (Koutcheiko et al. 2007).

Carbon content and nutrient status of feedstock and biochar: Pyrolysis alters the nutrient content in the resulting biochar, which therefore affects nutrient availability to plants. The increase in carbon and nutrient status is due to thermal humiliation which means, loss of volatile compounds ( $\mathrm{H}$ and $\mathrm{O}$ mainly) of the original material (Chan and $\mathrm{Xu} 2009$ ) and comparatively small losses of alkali nutrients by volatilization. The feedstock's influence on carbon and nutrient preservation in biochar varied extensively. 


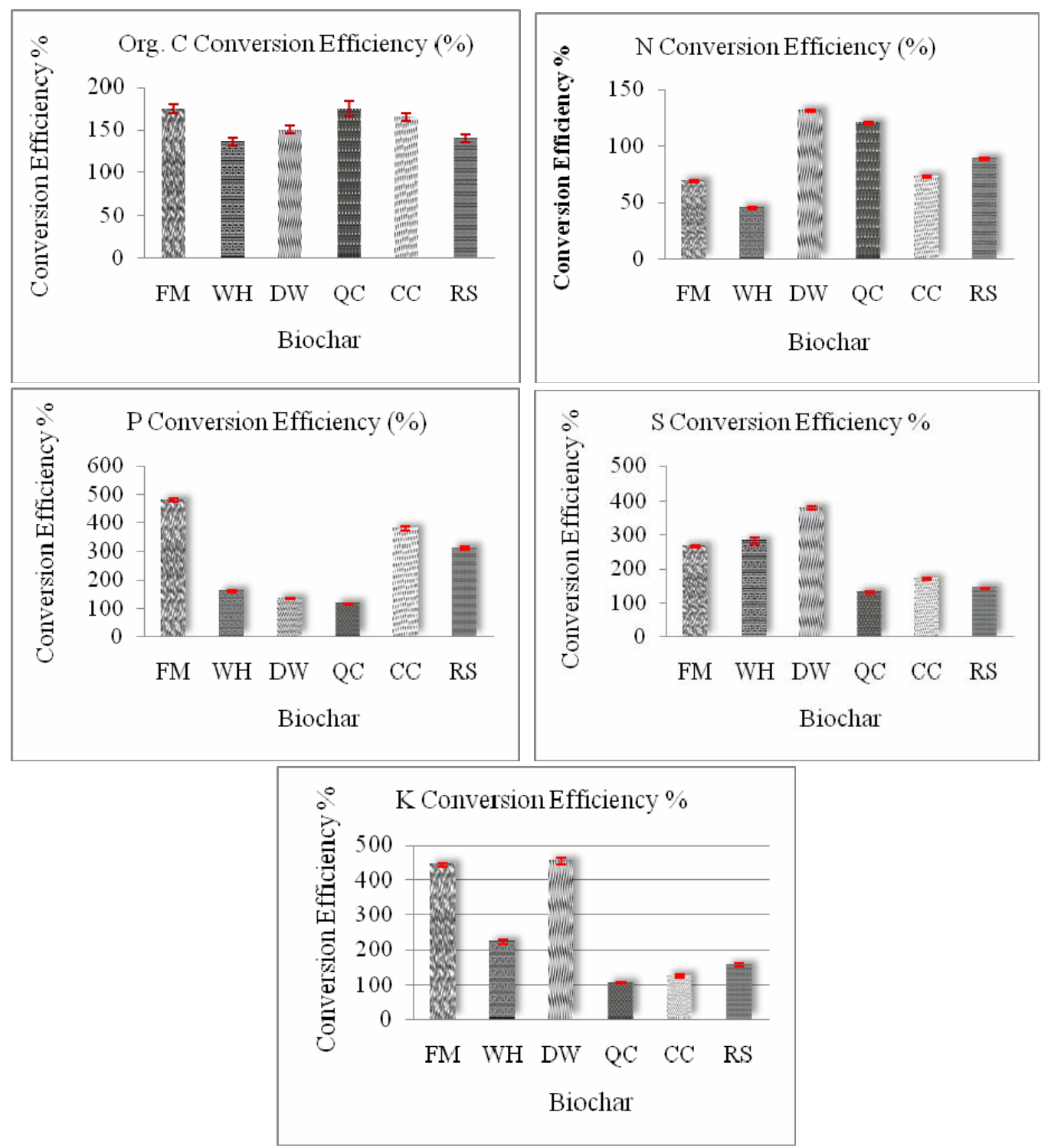

Fig. 5. Conversion efficiency of pyrolysis process to preserve C, N, P, S and K.

Organic carbon content of feedstock determined the restored carbon in biochar significantly ( $\mathrm{p} \leq$ 0.05). Carbon conversion efficiency (Fig. 5) ranged from nearly 130 to $175 \%$ depending on the used feedstock. Both FM and QC biochars carbon conversion efficiency was the highest $(175 \%)$ at $380^{\circ} \mathrm{C}$ and water hyacinth biochar demonstrated the lowest efficiency. It is commonly believed that, the raise in $\mathrm{C}$ content is a consequence of the reduction in overall biochar mass rather than additional ' $\mathrm{C}$-fixing' reactions. Table 2 implies structural adjustment and increased $\mathrm{C}$ storage in biochar due to carbonization reactions during pyrolysis. 
For example, high-temperature biochars exhibit a high degree of aromatic $\mathrm{C}$ structures (Novak et al. 2009) that are resistant to degradation as they don't provide labile fraction of $\mathrm{C}$ to soil microbes. Domestic organic waste and rice straw biochar possess the highest organic $\mathrm{C}$ content, respectively whereas corn cob biochar holds the lowest (34.96\%). This stable form of organic C would extensively affect physicochemical properties of soil.

However, total N, P, K and $\mathrm{S}$ content in biochar was not mainly determined by the concentrations in feedstock. Nitrogen conversion efficiency varied within about $45 \%$ to slightly over $125 \%$.

Table 2. Total organic C (\%) in feedstock and biochar.

\begin{tabular}{lllllll}
\hline Properties & FM & WH & DW & QC & CC & RS \\
\hline Feedstock Org. C & $23.5 \pm 1.18$ & $27.39 \pm 1.37$ & $32.56 \pm 1.63$ & $22.79 \pm 1.14$ & $21.2 \pm 0.97$ & $33.56 \pm 1.45$ \\
Biochar Org. C & $41.2 \pm 1.76$ & $37.22 \pm 2.06$ & $48.93 \pm 1.58$ & $39.98 \pm 2.34$ & $34.96 \pm 1.75$ & $47.14 \pm 1.87$ \\
\hline
\end{tabular}

' \pm ' standard deviation.

Table 4. Total nutrient (N, P, Kand S) status (\%) of biochars and feedstocks.

\begin{tabular}{lllllll}
\hline \multirow{2}{*}{ Nutrients } & \multicolumn{7}{c}{ Biochar } \\
\cline { 2 - 7 } & FM & WH & DW & QC & CC & RS \\
\hline $\mathrm{N}$ & $0.85 \pm 0.02$ & $1.04 \pm 0.03$ & $2.00 \pm 0.10$ & $1.99 \pm 0.12$ & $0.56 \pm 0.04$ & $0.82 \pm 0.03$ \\
$\mathrm{P}$ & $2.49 \pm 0.11$ & $1.99 \pm 0.13$ & $2.23 \pm 0.16$ & $1.51 \pm 0.07$ & $0.49 \pm 0.04$ & $0.56 \pm 0.02$ \\
$\mathrm{~K}$ & $2.88 \pm 0.13$ & $7.49 \pm 0.23$ & $7.04 \pm 0.18$ & $1.41 \pm 0.12$ & $1.51 \pm 0.08$ & $3.64 \pm 0.12$ \\
$\mathrm{~S}$ & $1.62 \pm 0.05$ & $1.92 \pm 0.04$ & $1.97 \pm 0.10$ & $0.97 \pm 0.05$ & $0.66 \pm 0.05$ & $0.77 \pm 0.03$ \\
\hline
\end{tabular}

(Table contd. right side)

\begin{tabular}{lllllll}
\hline \multirow{2}{*}{ Nutrients } & \multicolumn{7}{c}{ Feedstock } \\
\cline { 2 - 7 } & FM & WH & DW & QC & CC & RS \\
\hline $\mathrm{N}$ & $1.23 \pm 0.06$ & $2.3 \pm 0.09$ & $1.53 \pm 0.10$ & $1.68 \pm 0.07$ & $0.77 \pm 0.01$ & $0.92 \pm 0.03$ \\
$\mathrm{P}$ & $0.52 \pm 0.01$ & $1.24 \pm 0.10$ & $1.66 \pm 0.08$ & $1.30 \pm 0.11$ & $0.13 \pm 0.00$ & $0.18 \pm 0.01$ \\
$\mathrm{~K}$ & $0.65 \pm 0.07$ & $3.39 \pm 0.06$ & $1.55 \pm 0.03$ & $1.63 \pm 0.02$ & $1.23 \pm 0.05$ & $2.37 \pm 0.11$ \\
$\mathrm{~S}$ & $0.31 \pm 0.02$ & $0.38 \pm 0.03$ & $0.20 \pm 0.01$ & $0.44 \pm 0.03$ & $0.09 \pm 0.00$ & $0.24 \pm 0.01$ \\
\hline
\end{tabular}

' \pm ' standard deviation.

WH biochar demonstrated the lowest efficiency in $\mathrm{N}$ conversion whereas DW biochar exhibited the highest followed by quick compost both having around $2 \% \mathrm{~N}$ in feedstock. The $\mathrm{N}$ loss is facilitated with increasing pyrolysis temperature and the remaining $\mathrm{N}$ is transformed into heterocyclic-N (Zheng et al. 2013). Scientists reported that, the decrease in phyto-available $\mathrm{N}$ in high temperature biochar is due to the loss of total $\mathrm{N}$ and heterocyclization of $\mathrm{N}$ during pyrolysis 
(Koutcheiko et al. 2007) assuring the fact that total nutrient content may not always replicate the actual availability of nutrients to plants.

Pyrolysis process of biochar production generally loss a smaller amount of $\mathrm{P}$ than $\mathrm{C}$ or $\mathrm{N}$ as it is transformed to less soluble minerals resulting in reduction of available $\mathrm{P}$ in biochars (Zheng et al. 2013). Present study demonstrates higher $\mathrm{P}$ conversion efficiencies. Farmyard manure biochar showed about $450 \% \mathrm{P}$ conversion efficiency having $2.49 \% \mathrm{P}$ stored in it. Corn cob biochar illustrated second highest efficiency (390\%) though it had the lowest $(0.49 \%)$ concentration of P among the feedstocks. The WH, DW and QC biochar's total P increase can be attributed to the loss of $\mathrm{C}$ and relatively stable $\mathrm{P}$ formation. The soluble $\mathrm{P}$ in biochars produced in low temperature $\left(<400^{\circ} \mathrm{C}\right)$, become insoluble $\mathrm{Ca}$ and $\mathrm{Mg}$ minerals in the high temperature biochars (Zheng et al. 2013). Thus, the low temperature biochars like those in current study can be a good amendment to enhance P concentrations in deficient soils. Potassium conversion efficiency of produced biochars were the highest (100 to $460 \%$ ) among all the nutrients. This property can be attributed to very low volatilization loss of this element. Some observations disagree to the fact of no K loss occurs during pyrolysis. Yu et al. (2005) showed $48 \%$ loss of total K during pyrolysis of rice straw between 473 and $673^{\circ} \mathrm{C}$. We found $53 \%$ increase in $\mathrm{K}$ concentration of rice straw derived biochar. Unlike available $\mathrm{P}$ concentration, available $\mathrm{K}$ concentration increases with increasing temperature (Chan and $\mathrm{Xu} 2009$ ). The total $\mathrm{K}$ content in common organic fertilizers, poultry manure for instance was reported to be between 0.1 and 1.6\% (Chan and Xu 2009), but the biochars in this study ranged from 1.41 to $7.49 \%$.

The effects of feedstock type and its conversion processes on the speciation of sulfur in biochars are not well-understood yet. Sulfur content in biochars vary depending on biochar production processes like pyrolysis or gasification $\left(>700^{\circ} \mathrm{C}\right)$. In this study sulfur content of pyrolyzed biochars varied from slightly over $0.5 \%$ (corn cob) to about $2 \%$ (water hyacinth and domestic organic waste). Cheah et al. (2014) reported that pyrolyzed biochars $\left(500-600^{\circ} \mathrm{C}\right)$ mainly contain sulfate (77 - 100\%), organosulfur, and sulfide whereas gasification biochars contain $73-100 \%$ organosulfur.

\section{Conclusion}

Biochars demonstrated varying levels of physico-chemical properties and nutrient content. Water hyacinth biochar showed high BET specific surface area, water holding and cation exchange capacity while Domestic organic waste biochar had enhanced essential nutrient content. Hence, Feedstocks for biochar production must be carefully selected to meet the needs of a particular soilcrop combination. The biochars used in this study are easily available and some possesses high potentiality to adopt in the agricultural system. However, cost-benefit ratio, production process, effect of production temperature and socioeconomic factors should be considered before field application. 


\section{References}

American Society for Testing and Materials (ASTM). 2010. Standard test methods for laboratory determination of water (moisture) content of soil and rock by mass. In: D 2216-10, Annual Book of ASTM Standard, ASTM International, West Conshohocken, PA. pp. 1-8.

Ayodele, A., P. Oguntunde, A. Joseph and M. D. S. Dias Jr. 2009. Numerical analysis of the impact of charcoal production on soil hydrological behavior, runoff response and erosion susceptibility. Rev. Bras. Cienc. Solo. 33: 137-145.

Cabrera, A., L. Cox, K. A. Spokas, R. Celis, M. C. Hermosin, J. Cornejo and W. C. Koskinen. 2011. Comparative sorption and leaching study of the herbicides fluometuron and 4-Chloro-2methylphenoxyacetic acid (MCPA) in a soil amended with biochars and other sorbents. J. Agric. Food Chem. 59: 12550-12560.

Chan, K. Y. and Z. Xu. 2009. Biochar: Nutrient properties and their enhancement. In: J. Lehmann and S. Joseph (eds.). Biochar for Environmental Management: Science and Technology. Earthscan, London. pp. 53-66.

Cheah, S., S. C. Malone and C. J. Feik. 2014. Speciation of sulfur in biochar produced from pyrolysis and gasification of oak and corn stover. Environ. Sci. Technol. 48: 8474-8480.

Deenik, J. L., T. McClellan, G. Uehara, M. J. Antal and S. Campbell. 2010. Charcoal volatile matter content influences plant growth and soil nitrogen transformations. Soil Sci. Soc. Am. J. 74: 1259-1270.

Enders, A., K. Hanley, T. Whitman, S. Joseph and J. Lehmann. 2012. Characterization of biochars to evaluate recalcitrance and agronomic performance. Bioresource Technol. 114: 644-653.

Jackson, M. L. 1962. Soil Chemical Analysis. Prentice Hall Inc., Englewood Cliffs N. J., USA. pp. 498.

Koutcheiko, S., C. M. Monreal, H. Kodama, T. McCracken and L. Kotlyar. 2007. Preparation and characterization of activated carbon derived from the thermo-chemical conversion of chicken manure. Bioresource Technol. 98: 2459-2464.

Lehmann, J., M. Rillig, J. Thies, C. A. Masiello, W. C. Hockaday and D. Crowley. 2011. Biochar effects on soil biota- A review. Soil Biol. Biochem. 43: 1812-1836.

Meszaros, E., E. Jakab, G. Varhegyi, J. Bourke, M. ManleyHarris, T. Nunoura and M. J. Antal. 2007. Do all carbonized charcoals have the same chemical structure? Implications of thermogravimetry mass spectrometry measurements. Ind. Eng. Chem. Res. 46: 5943-5953.

Naeem, M. A., M. Khalid, M. Arshad and A. Rashid. 2014. Yield and nutrient composition of biochar produced from different feedstocks at varying pyrolytic temperatures. Pak. J. Agri. Sci. 51(1): 75-82.

Novak, J. M., I. M. Lima, B. Xing, J. W. Gaskin, C. Steiner, K. C. Das, M. Ahmedna, D. Rehrah, D. W. Watts, W. J. Busscher and H. Schomberg. 2009. Charcaterization of designer biochar produced at different temperatures and their effects on a loamy sand. Ann. Environ. Sci. 3: 195-206.

Preston, C. M. and M. W. I. Schmidt. 2006. Black (pyrogenic) carbon: A synthesis of current knowledge and uncertainties with special consideration of boreal regions. Biogeosciences. 3: 397-420.

Qayyum, M. F., D. Steffens, H. P. Reisenauer and S. Schubert. 2014. Biochars influence differential distribution and chemical composition of soil organic matter. Plant Soil Environ. 60(8): 337-343.

Rayment, G. E. and F. R. Higginson. 1992. Australian Laboratory Handbook of Soil and Water Chemical Methods. Inkata Press, Melbourne. pp. 330.

Ronsse, F., S. V. Hecke, D. Dickinson and W. Prins. 2013. Production and characterization of slow pyrolysis biochar: Influence of feedstock type and pyrolysis conditions. GCB Bioenerg. 5: 104-115. 
Rutherford, D. W., R. L. Wershaw, C. E. Rostad and C. N. Kelly. 2013. Effect of formation conditions on biochars: Compositional and structural properties of cellulose, lignin, and pine biochars. Biomass Bioenerg. 46: 693-701.

Sposito, G. 1989. The Chemistry of Soils.Oxford University Press, New York, NY. pp. 344.

Walkley, A. and I. A. Black. 1934. An examination of Degtjareff method for determining soil organic matter and a proposed modification of the chromic acid titration method. Soil Sci. 37: 29-37.

Yu, C., Y. Tang, M. Fang, Z. Luo and K. Chen. 2005. Experimental study on alkali emission during rice straw pyrolysis. J. Zhejiang Univ. (Eng. Sci.) 39: 1435-1444.

Zheng, H., Z. Wang, X. Deng, J. Zhao, Y. Luo, J. Novak, S. Herbert and B. Xing. 2013. Characteristics and nutrient values of biochars produced from giant reed at different temperatures. Bioresource Technol. 130: 463-471.

(Manuscript received on 5 December, 2016; revised on 8 January, 2017) 